Revista Universo Contábil, ISSN 1809-3337

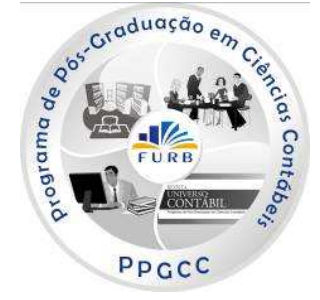

\title{
EL APRENDIZAJE DE LOS FUNDAMENTOS CONTABLES BASADO EN EL ENFOQUE DEL PROCESO PRIMARIO*
}

\section{LEARNING THE FUNDAMENTALS OF ACCOUNTING BASED ON THE PRIMARY PROCESS PERSPECTIVE}

\section{Berta Silva Palavecinos}

Doctoranda en Ciencias Empresariales de la Universidad Autónoma de Madrid Profesora de la Escuela de Comercio de la Pontificia Universidad Católica de Valparaíso

Dirección: Av. Brasil, n. 2830

CEP: 2340031 - Valparaíso - Chile

E-mail: bsilva@ucv.cl

Teléfono: 56(32)227-3329

\section{RESUMEN}

El objetivo de este trabajo es presentar un método para la enseñanza de la contabilidad que ha sido desarrollado desde el año 1996 (SILVA, 1996), basándose en un modelo propuesto en la década del ochenta por un grupo de profesores de la Escuela de Comercio en la Universidad Católica de Valparaíso, en Chile. Para alcanzar el objetivo propuesto se realiza un trabajo descriptivo que revela cómo a partir de un método básico la autora ha realizado importantes cambios a través de los años, que ha permitido generar un método para facilitar la enseñanza de la contabilidad. El método ha sido practicado con sus propios estudiantes y lo ha compartido con otros docentes, nacionales y extranjeros, quienes lo han puesto en práctica y han reconocido la utilidad que tiene para que los educandos realicen el aprendizaje de la contabilidad de una manera más dinámica, logrando resolver con un enfoque más analítico los problemas formulados en materias contables. La adopción a nivel mundial de las Normas Internacionales de Información Financiera (IFRS), conjunto de normas en que lo más importante es que se reconozcan, se midan y se revelen los efectos sobre activos, pasivos y patrimonio que derivan de los hechos económicos, enfatizando el fondo por sobre la forma de los mismos, requiere la preparación de un profesional de la disciplina contable que posea una mayor capacidad analítica.

Palabras-clave: Metodología. Aprendizaje de la contabilidad. Proceso primario. Dualidad económica.

Artigo recebido em 09.07.2009. Revisado por pares em 02.11.2009. Reformulado em 16.12.2009. Recomendado em 17.12.2009 por Ilse Maria Beuren (Editora). Publicado em 02.02.2010. Organização responsável pelo periódico: FURB. 


\section{RESUMO}

O objetivo do estudo é apresentar um método para o ensino da contabilidade que foi desenvolvido desde o ano de 1996 (SILVA, 1996), baseando-se no modelo proposto na década de oitenta por um grupo de professores da Escola de Comércio na Universidade Católica de Valparaíso, no Chile. Para alcançar o objetivo proposto se efetuou um estudo descritivo, que revela como a partir de um método básico, a autora realizou importantes mudanças através dos anos, que permitiu gerar um método para facilitar o ensino da contabilidade. O método foi praticado pelos seus próprios alunos e foi compartilhado com outros docentes, nacionais e estrangeiros, que o colocaram em prática e reconheceram a sua utilidade para que os educandos realizassem o aprendizado da contabilidade de uma maneira mais dinâmica, conseguindo resolver com um enfoque mais analítico os problemas formulados em matérias contábeis. A adoção em âmbito mundial das Normas Internacionais de Informação Financeira (IFRS), conjunto de normas em que o mais importante é que se reconheça, mensure e revele os efeitos sobre ativos, passivos e patrimônio que derivam dos fatos econômicos, enfatizando a essência sobre a forma dos mesmos, requer a preparação de um profissional da disciplina contábil que possua maior capacidade analítica.

Palavras-chave: Metodologia. Aprendizagem da contabilidade. Processo primário. Dualidade econômica.

\section{ABSTRACT}

The aim of this paper is to present a method for teaching accounting that has been developed since 1996 (SILVA, 1996), based on a model proposed in the eighties by a group of teachers at the School of Commerce in the Catholic University of Valparaiso, Chile. To achieve the proposed objective a descriptive study was done, revealing how, from a basic method, the author has made significant changes over the years, allowing the development of a method to facilitate the teaching of accounting. The method was practiced by her own students and shared with other teachers, domestic and foreign, who have implemented it and have recognized the usefulness for the students to make the learning of accounting more dynamic, solving with a more analytical approach the problems raised in accounting issues. The worldwide adoption of International Financial Reporting Standards (IFRS), set of rules in which the most important is to recognize, measure and reveal effects on assets, liabilities and equities resulting from economic events, requires the preparation of an accounting professional that has greater analytical skills.

Keywords: Methodology. Accounting learning. Primary process. Economic duality.

\section{INTRODUCCIÓN}

Actualmente la armonización contable con las normas internacionales de contabilidad emitidas por el International Accounting Standards Board (IASB) constituye una preocupación en distintos países del mundo. En estas normas se establecen los criterios o fundamentos que se deben o se pueden seguir, según el caso, para efectuar el reconocimiento y la medición inicial y posterior de los activos y de los pasivos. Es pertinente señalar que la normativa emitida por este organismo enfatiza el fondo económico de los eventos y los efectos que persigue reconocer, medir y revelar; en ella se destacan los criterios a aplicar según la naturaleza del evento más que a establecer reglas específicas para el registro, valoración y revelación pertinente de cada uno específicamente. Por tal razón, será cada vez 
más importante que los educandos en la disciplina contable sean formados con énfasis en el desarrollo de su capacidad de análisis, y no en el conocimiento exclusivamente técnico.

El objetivo de este trabajo es presentar un método para la enseñanza de la contabilidad que ha sido desarrollado desde el año 1996 (SILVA, 1996), basándose en un modelo propuesto en la década del ochenta por un grupo de profesores de la Escuela de Comercio en la Universidad Católica de Valparaíso, en Chile.

Para alcanzar el objetivo propuesto se realiza un trabajo descriptivo que revela cómo a partir de un método básico la autora ha realizado importantes cambios a través de los años, que ha permitido generar un método para facilitar la enseñanza de la contabilidad. El método ha sido practicado con sus propios estudiantes y lo ha compartido con otros docentes, nacionales y extranjeros, evidencia en Silva (2008), quienes lo han puesto en práctica y han reconocido la utilidad que tiene para que los educandos realicen el aprendizaje de la contabilidad de una manera más dinámica, logrando resolver con un enfoque más analítico los problemas formulados en materias contables. El método presentado se encuentra plasmado en el libro Fundamentos del sistema contable. Nuevos enfoques y actualización (SILVA, 2006), incorporado en la bibliografía para la enseñanza de la contabilidad básica de distintas universidades chilenas y por tanto ha sido probado por otros docentes que coinciden que es una metodología adecuada y útil.

Por años se han utilizado en las bibliografías de los programas de formación en contabilidad, textos que se circunscriben a enfoques clásicos de enseñanza, es decir, a partir de la ecuación contable, que por enfatizar el cambio de estado de la estructura patrimonial con cada hecho económico y no en el hecho mismo y sus efectos, constituye una concepción estática del quehacer de los negocios. Se puede señalar autores extranjeros tales como Warren, Reeve, Tess y Philip (2000); Meigs, Haka y Bettner (2000); Horngren, Sundem y Elliot (2000); Meigs, Meigs, Bettner y Whittington (1998); Cantú (1995) y autores nacionales tales como: Torres (2.000); Bosch y Vargas (1995); Nicolini y Soto (1978).

Los profesores, generalmente enseñan lo que es la partida doble y su aplicación, es decir el énfasis está en cómo registrar las transacciones relacionadas con la empresa, por lo tanto, el educando es preparado en el campo del hacer de la contabilidad, y no en fundamentar ese quehacer o sea en establecer el por qué de ese hacer (GARCÍA, 2001). Regularmente se confunden o se usan como sinónimos los términos dualidad económica y partida doble, siendo que el primero es conceptual y en él se basa la técnica de registro a la cual se refiere el segundo concepto.

En la enseñanza de la contabilidad a partir del modelo de la ecuación contable, el énfasis se coloca en el registro de las operaciones y como cada una de ellas afecta a la estructura de recursos de la empresa, es decir al estado de situación financiera (balance) y no se ocupa de que el educando interiorice y reconozca los distintos flujos de recursos y/o de obligaciones que va generando cada transacción realizada por la empresa, las causas y efectos de los cambios patrimoniales y ello no favorece una formación acorde con la evolución que sufre la disciplina contable. A menudo se pone el mayor énfasis en el conjunto de normas contables, y se resta importancia al Marco Conceptual que establece el marco teórico con las hipótesis y conceptos básicos, indispensables para la adecuada comprensión de ese cuerpo normativo.

A través del modelo de enseñanza de la contabilidad a partir del proceso primario, el aprendizaje de la disciplina se orienta a comprender el funcionamiento de la empresa, de los procesos que desarrolla internamente y en la interacción con el medio y los flujos de recursos desde y hacia ella, que permiten comprender el concepto fundamental en el cual se sustenta la partida doble y esto es la dualidad económica. Este modelo facilita el conocimiento y comprensión del objeto de estudio de la contabilidad, es decir los flujos de 
recursos y sus transformaciones y de cómo se generan los cambios en la estructura de inversión y financiamiento de la empresa, así como en su patrimonio.

Una metodología para la enseñanza de la contabilidad a partir del proceso primario analizado desde la perspectiva de la dualidad económica. es considerada más adecuada, más pertinente ya que pone énfasis en el por qué hacer, en el fundamento del reconocimiento, valorización y revelación de cada hecho económico, privilegiando lo conceptual por sobre la técnica, ya que esta última solamente explica el cómo hacer y no el por qué del hacer. Aprender contabilidad desde esta perspectiva, permite desarrollar una capacidad analítica que otorga al educando una mayor habilidad para enfrentar y resolver situaciones inéditas, es lo que concluye Silva $(2006,2003,2002,1997,1996)$.

\section{ORIGEN DE LA METODOLOGÍA}

En la XI Jornadas de Ciencias Económicas del ConoSur los autores Alvarez; García y Nattero (1983) propusieron una metodología docente para el área contable en la formación del contador, en la que se enfatizaba la enseñanza a partir del proceso primario y de un principio contable fenomenológico, la dualidad económica.

En la ponencia señalaron que la contabilidad no es una función aislada, sino que está inserta en el sistema-empresa y que al analizar la empresa a partir del proceso primario, conocido en el lenguaje contable financiero como el ciclo operacional, se pueden distinguir las diferentes transformaciones de sus flujos, cuya comprensión es básica para entender el objeto de medición de la disciplina contable, el cual es la empresa a través de los flujos y acumulaciones de recursos. La motivación de estos docentes fue proponer una mejor manera para entregar los fundamentos de la disciplina contable al profesional, quien tendrá que actuar en un mundo cambiante a ritmo acelerado. Con esta metodología se buscaba permitir al educando pensar con autonomía a partir de la aprehensión de los fundamentos de la disciplina.

Los autores, también señalaron que bajo la óptica del proceso primario se pueden ordenar todos los aspectos contables que digan relación con las transformaciones que dan origen a este proceso, dando al educando la posibilidad de relacionar la contabilidad con el funcionamiento básico de la empresa. De esta manera, se puede analizar, para cada transformación, los aspectos de entrada, procesamiento y salida de información, que son relevantes para la empresa, es decir se va relacionando la información con los datos necesarios para obtenerla, con el procesamiento y con los informes finales. Para explicar la aplicación del método, los proponentes Alvarez, García y Nattero (1983) utilizaron el esquema simplificado del proceso primario (Figura 1) y el esquema de la conversión del proceso en el sistema contable (Figura 2).

Se puede observar que en el primer esquema queda excluida la transformación correspondiente a la función de Personal, indispensable para realizar las transformaciones restantes. En el segundo esquema simplifica el modelo señalando el Balance (estado de la situación financiera) como la salida de Información, esto podría llevar al lector a pensar que solamente se genera este informe del proceso contable. Los autores señalaron que con la estructura de estos esquemas in mente, es posible comprender con facilidad y dentro de una totalidad, los conceptos de patrimonio, dualidad económica y su formalización en la ecuación contable, balance y estado de resultados, puesto que el marco teórico no se refiere a la contabilización aislada, sino dentro de un contexto que permite dar cuenta del hecho económico observado dentro de un sistema organizacional. 


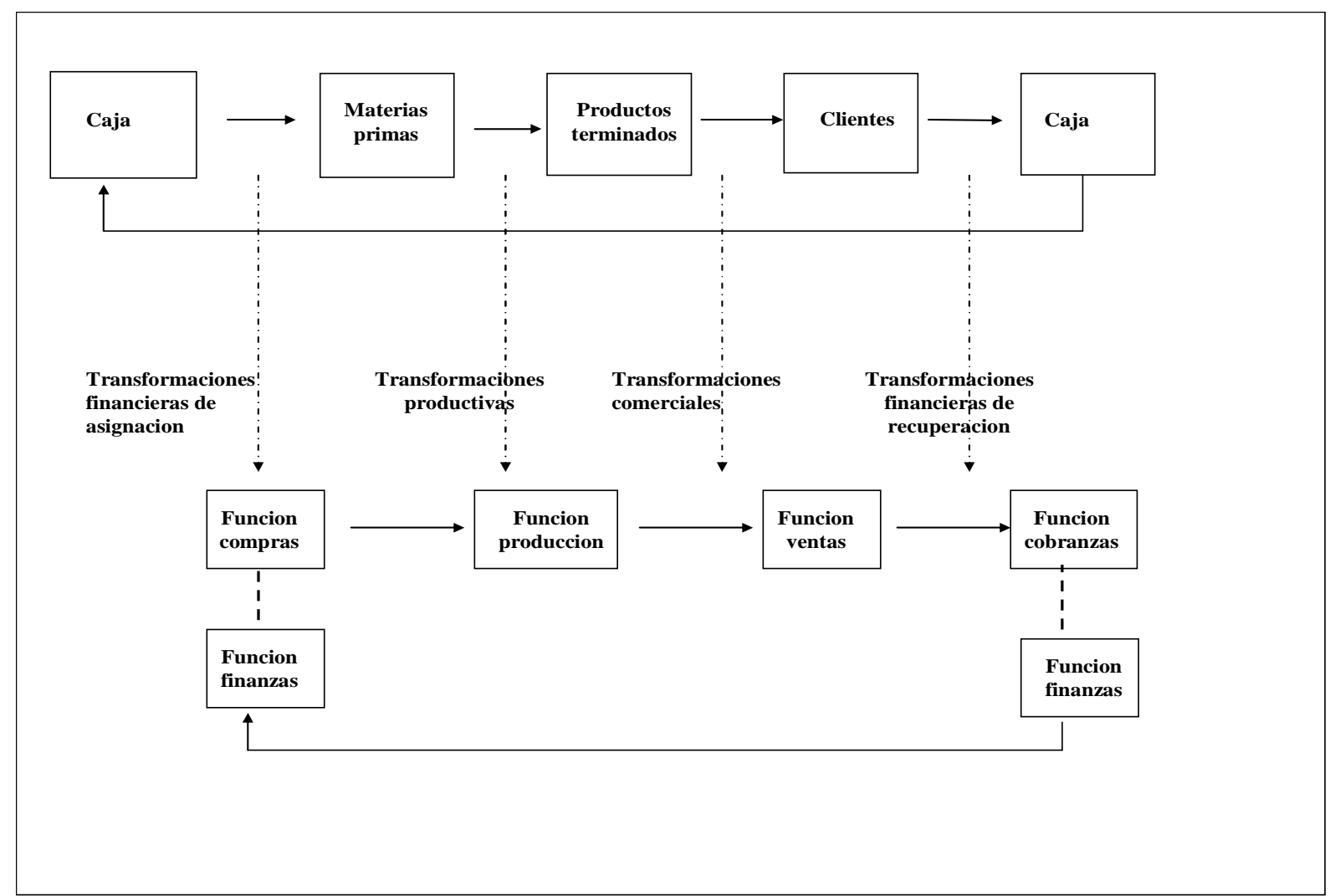

Figura 1 - Proceso primario - esquema simplificado

Fuente: adaptación de Alvarez, García y Nattero (1983).

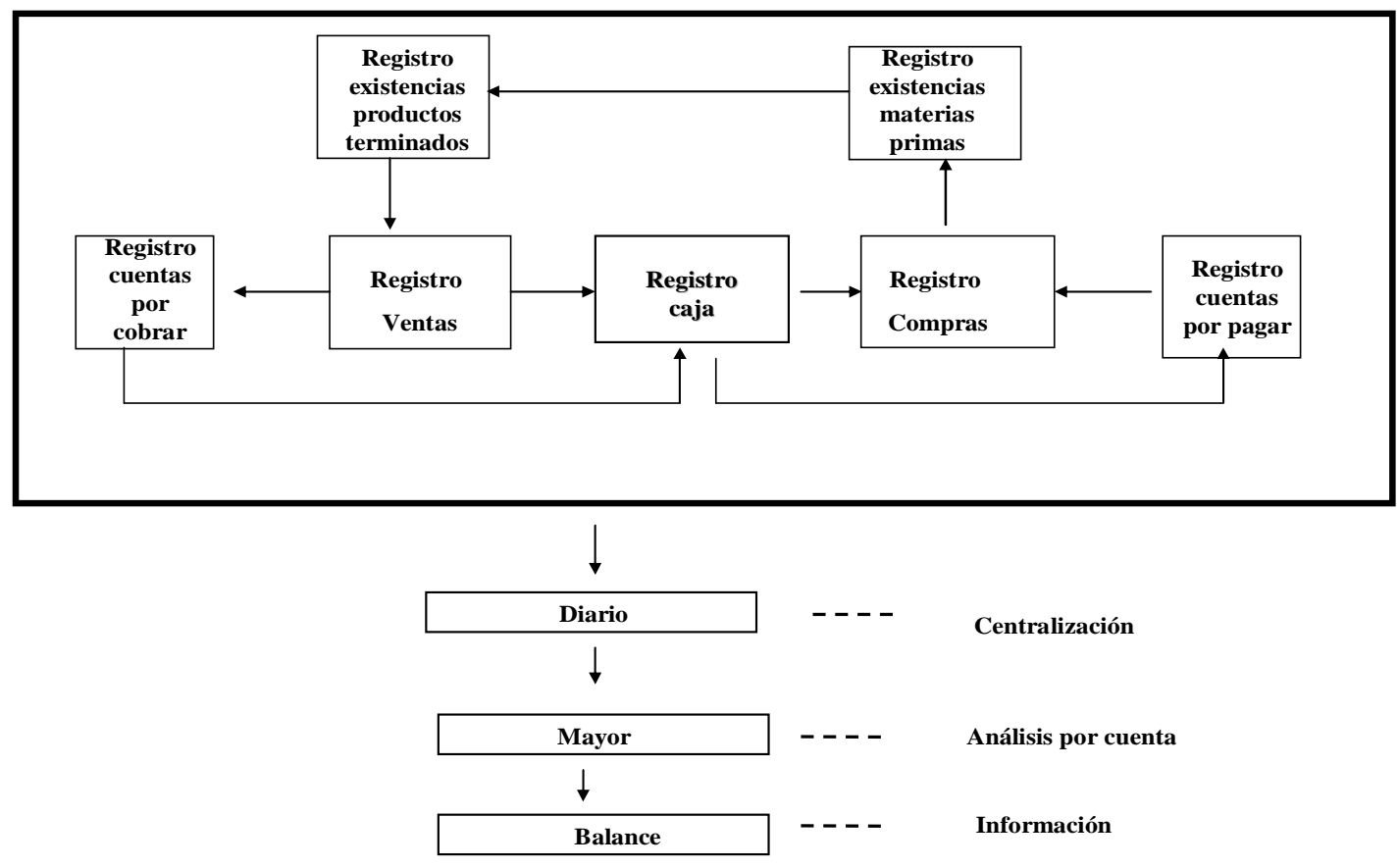

Figura 2 - Conversión del proceso primario en el sistema contable Fuente: Alvarez, García y Nattero (1983). 
Los autores supusieron que el ciclo se inicia con determinado monto de efectivo y que el incremento o decremento que se genera en ese nivel de efectivo durante el período corresponde a la variación patrimonial, este supuesto encierra el peligro que un neófito en materias de la disciplina contable, concluya que la variación patrimonial se materializa en variaciones del nivel de caja, lo que está muy alejado de la verdad, y además atenta contra la comprensión del concepto de devengado. Indicaban, que por otra parte el nivel de efectivo inicial tiene su origen en recursos entregados por los dueños de la empresa o por terceros. Aquí existe la primera idea de fuentes y usos de recursos. Estos recursos se van transformando, durante el proceso, en bienes que constituyen los activos necesarios para el giro del negocio, cuyo objetivo es la producción de productos terminados. Estos al ser vendidos, generan efectivo que en definitiva constituye una fuente, de recursos que retroalimenta el proceso primario.

De este proceso nace la idea de dualidad económica: los recursos que ingresaron (fuentes) al proceso, tienen que ser iguales a los recursos que se utilizaron en éste (usos). Los autores al referirse a esta metodología docente propuesta se proponían que los educandos, desde el comienzo, tuvieran una formación teórica que les permitiese abordar los problemas contables en su contexto global, y en la medida que avanzaran en ese conocimiento, se les entregara los aspectos operativos y una reflexión sobre la teoría necesaria para dar cuenta de esos problemas operacionales. Los objetivos generales a alcanzar eran que los educandos llegaran a conocer y comprender la función contable y su alcance; a relacionar la función contable y sus objetivos, tanto con el entorno en el que se encuentra inserta la empresa, como con las distintas áreas funcionales y niveles estructurales de ella; y a reconocer la incidencia de la función contable en los procesos decisionales, en las instancias de control y en la función de planificación, y poder interactuar profesionalmente con estas funciones.

\section{ENFOQUES DE APRENDIZAJE DE LA CONTABILIDAD}

El propósito que se le ha otorgado a la contabilidad, ha determinado la necesidad de que exista un método de aprendizaje de esta disciplina que se adecue al mismo. Podemos ir desde un enfoque en el cual el propósito es establecer y medir o valorar los elementos contables que conforman la estructura patrimonial, hasta un enfoque que proporcione el desarrollo de la capacidad analítica del responsable del reconocimiento, la medición y la exposición o revelación de la información que resulta del proceso contable.

Entendiendo por estructura patrimonial al conjunto de todos los activos y pasivos de una empresa u organización, podemos afirmar, que en general, los profesionales que se desenvuelven en el ámbito de la disciplina contable han sido formados en la enseñanza de la contabilidad a partir de la ecuación contable y sus transformaciones. Por ejemplo, autores internacionales tales como: Warren, Reeve, Tess y Philip (2000); Meigs, Haka y Bettner (2000); Horngren, Sundem y Elliot (2000); Meigs, Meigs, Bettner y Whittington (1998); Cantú (1995). Y autores nacionales tales como: Torres (2.000); Bosch y Vargas (1995); Nicolini y Soto (1978).

Este enfoque pone énfasis en un cambio de estado de la estructura patrimonial (como queda ésta después de registrar el evento económico) y, no en las causas y efectos del evento que genera el cambio estructural. Por años se han utilizado en las bibliografías de los programas de formación en contabilidad, textos que se circunscriben a enfoques clásicos de enseñanza, es decir, a partir de la ecuación contable, que por enfatizar el cambio de estado de la estructura patrimonial con cada hecho económico y no en el hecho mismo y sus efectos, constituye una concepción estática del quehacer de los negocios. 
Si se abordara tal formación, desde la perspectiva del estudio de la dualidad económica a partir del proceso primario, el énfasis se colocaría en el fundamento teórico contable que está presente en los distintos hechos económicos que deben ser reconocidos, medidos y revelados por el sistema contable, que constituye un elemento componente del sistema de información de una organización o entidad, es lo que propone Silva $(2006,2003$, 2002, 1997, 1996).

\section{PROCESO PRIMARIO}

El proceso primario es el conjunto secuencial de transformaciones, realizadas en y por la empresa, que tiene por objeto la regeneración de los fondos consumidos en el mantenimiento de su estructura y de los fondos utilizados en esas transformaciones (LIMONE, 1978) y ha sido representado por ese autor como aparece en la Figura 3. El concepto pone énfasis en las transformaciones que experimentan los flujos de recursos en el ciclo operacional de una empresa y cuya comprensión es necesaria para entender el objeto de medición de la contabilidad, es decir, los flujos y acumulaciones de recursos.

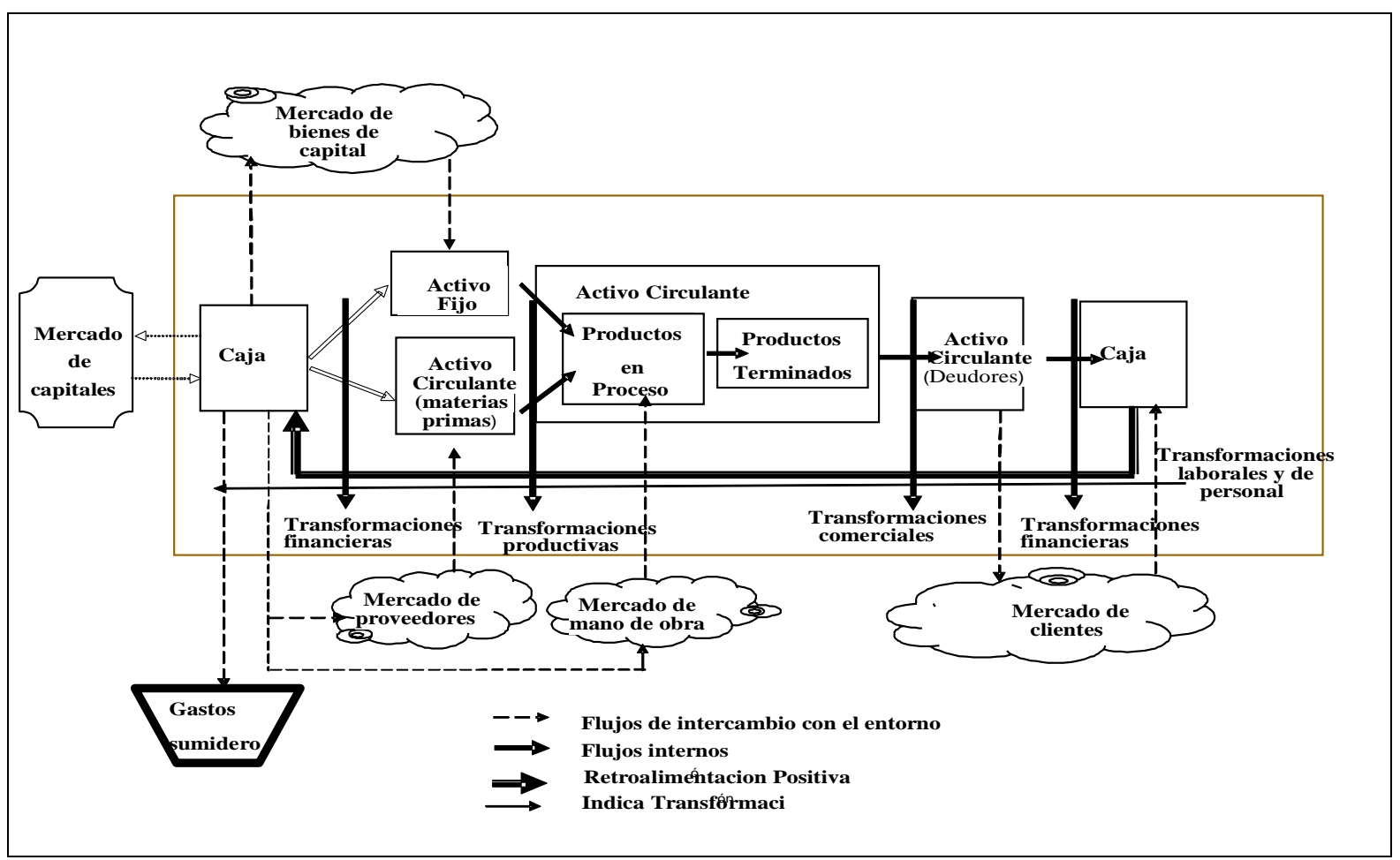

Figura 3 - Proceso primario

Fuente: Limone (1978).

En el ciclo operacional se distinguen las transformaciones financieras, de obtención de recursos financieros, que se realiza desde el mercado financiero sea con aportes de capital o con créditos obtenidos de acreedores. También pueden ser recursos provenientes de transformaciones financieras de recuperación, es decir, de la conversión de los derechos a cobrar en dinero disponible (cobranzas) y las transformaciones financieras de asignación de recursos, que corresponden a la conversión de dinero ya sean en bienes, servicios, inversiones, valores y otros. Se relaciona fundamentalmente a la función de compras, también denominada adquisiciones.

Se distinguen las transformaciones productivas, corresponden a la función de producción, es decir a la transformación de bienes, servicios y trabajo en productos y/o 
nuevos servicios; las transformaciones comerciales, corresponden a la conversión de los productos y/o servicios en derechos a cobrar a los clientes. Esta transformación se realiza a través de la entrega de los productos y/o servicios a los consumidores y las transformaciones laborales, consisten en el consumo de fuerza laboral (física o intelectual) en el desarrollo de las otras transformaciones. Se relaciona a la función de personal (SILVA, 2006).

En el desarrollo de este ciclo fluyen y se transforman recursos, materiales e inmateriales, de manera iterativa. En este ciclo se consumen y utilizan recursos para mantener la estructura y el funcionamiento de la empresa, los que deben ser recuperados a través del desarrollo del mismo ciclo y mientras la empresa continúe en funcionamiento, el ciclo operacional termina donde empieza, y se reactiva inmediatamente con el uso de los recursos disponibles y con cada unidad monetaria que queda disponible para algún uso alternativo dentro del mismo, siendo la asignación de los recursos realizada por un tomador de decisiones (agente decisor). Otro aspecto a considerar es la retroalimentación positiva que se produce en el proceso y que asegura el crecimiento de la empresa, ella comprende la asignación de recursos materiales, humanos, símbolos y energía para que prosiga el desarrollo del ciclo operacional básico.

Este ciclo puede durar más o menos de un período de tiempo predefinido y utilizado para hacer las mediciones y reconocimientos relacionados con estas transformaciones (período contable), generalmente se repite muchas veces durante un mismo período de tiempo, además, se podría afirmar que el sistema se retroalimenta a si mismo, se auto mantiene y mientras esto ocurra puede permanecer indefinidamente en funcionamiento (empresa en marcha).

En el ciclo operacional está siempre presente el concepto de dualidad económica, es decir, los recursos que se utilizan y/o mantienen en el proceso de transformaciones se igualan o corresponden a las fuentes que los generan. La dualidad económica se distingue como un principio fenomenológico de la contabilidad.

En el modelo expuesto, el ciclo operacional comienza en un determinado nivel de recursos (efectivo) que tienen su origen en el aporte de los dueños de la empresa o han sido proporcionados por terceros, a quienes se les adeudan (denominados en términos generales los acreedores). Estos recursos se van transformando durante el ciclo en bienes que constituyen los activos necesarios para desarrollar el giro del negocio, y que al ser vendidos generan nuevos recursos que sirven para recuperar aquellos consumidos en las transformaciones realizadas, en el mantenimiento de la estructura de la empresa, y también para auto generar otros.

\section{MEJORAS AL MODELO DEL PROCESO PRIMARIO}

Anteriormente se señaló que el supuesto de que el ciclo se inicia con determinado monto de efectivo y que el incremento o decremento que se genera en ese nivel de efectivo durante el período corresponde a la variación patrimonial, constituía una limitación en el modelo. Ella consiste en la posibilidad de confundir las variaciones patrimoniales y las variaciones de caja y de dificultar la comprensión del concepto de devengado, base contable que se utiliza y que además constituye un supuesto fundamental establecido en el marco conceptual de IASB.

El concepto de devengado, que requiere el reconocimiento de derechos y de obligaciones, formula que en la contabilidad se debe registrar lo percibido, y lo efectivamente pagado, como también, aquello que está por recibirse o adeudado. Esto significa que los efectos de las operaciones y de otros hechos (transformaciones) se deben reconocer cuando ocurren y no cuando el efectivo o su equivalente se cobra o se paga: se contabilizan en los registros contables y se revelan en los informes contables de los períodos a los cuales se 
refieren diferenciando transformaciones comerciales (cuando se perfecciona la venta) de las transformaciones financieras (cuando se realiza la cobranza), lo mismo diferenciando las transformaciones de adquisiciones, de compras de las transformaciones de pagos. Debido a esto, los resultados de un período incluyen todos los recursos y obligaciones, aún cuando estos no hayan sido percibidos o pagados.

Si se observa la Figura 3 referida al proceso primario se podrá advertir que la gráfica de los gastos se relaciona a la gráfica de caja, esto es válido bajo el supuesto planteado por su creador (LIMONE, 1977). El modelo original fue planteado para facilitar la comprensión de la relación entre las disciplinas de la administración, finanzas y contabilidad, no obstante, no contribuye a la formación rigurosa en los conceptos de la disciplina contable, ya que al utilizarlo en el aprendizaje de la contabilidad y sus supuestos fundamentales más bien fija la idea, que en general tiene todo neófito en materias contables, y que es creer que gasto es sinónimo de desembolso, es decir de salida de dinero, por tal razón se propuso una modificación al modelo básico del proceso primario (Figura 4a) que se presenta en la última versión formulada por la autora (SILVA, 2008).

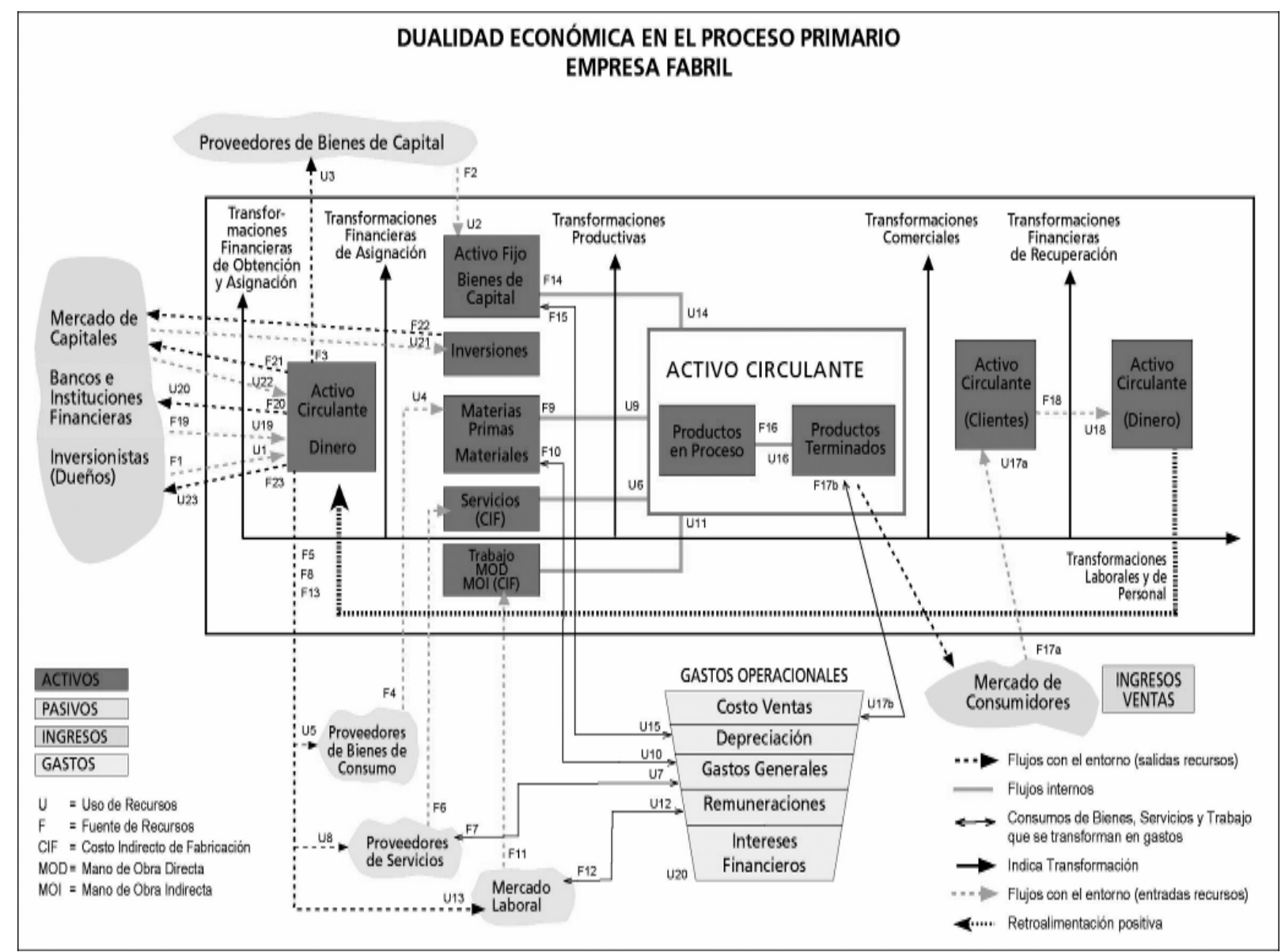

Figura 4a - Dualidad económica en el proceso primario de una empresa fabril

Fuente: adaptación Limone (2008).

En la Figura 4a se puede observar que se han incorporado nuevos elementos necesarios para enseñar contabilidad a partir del modelo del proceso primario.

a) Expresión de la dualidad económica que se encuentra presente en cada transformación que ocurre en la empresa, ya sea internamente o en interacción con el medio, designando los usos como U y las fuentes como F. Se puede observar 
como un mismo elemento contable (sea identificado como activo o como pasivo) puede constituir oso en algunos eventos y fuente en otros;

b) Comprensión del concepto de devengado ya que permite observar el reconocimiento de obligaciones (cuentas por pagar) y de derechos (cuentas por cobrar);

c) Presentación de los gastos ya no relacionados a la gráfica de caja sino a los usos y la oportunidad en que estos ocurren;

d) Distinción en el tratamiento de los consumos que se deben activar por ser considerados parte del costo de un activo en formación (productos en proceso) de aquellos que constituyen gastos. Al incorporar las gráficas, una referida a servicios y la otra referida a trabajo se puede enfatizar como el consumo de servicios y trabajo cuando son utilizados en el proceso de fabricación se deben incorporar al valor del activo que se fabrica, esta relación se puede observar en $\left(\mathrm{U}_{6}, \mathrm{~F}_{6}\right)$ y $\left(\mathrm{U}_{11}, \mathrm{~F}_{11}\right)$, en cambio cuando el consumo de los mismos ocurre en el desarrollo de actividades que no se vinculan a este proceso de fabricación se deben reconocer como gastos, esto ocurre en $\left(\mathrm{U}_{7}, \mathrm{~F}_{7}\right)$ y $\left(\mathrm{U}_{12}, \mathrm{~F}_{12}\right)$. Al explicar la conexión entre el entorno (los proveedores de servicios) con la empresa a través de la gráfica servicios con los productos en proceso, al educando se le prepara para alcanzar una mejor comprensión de los elementos del costo del producto, permite explicar el concepto de costo indirecto de fabricación conocido como CIF o GIF;

e) Distinción de los distintos elementos contables: activos, pasivos, gastos, ingresos, patrimonio. Identificación de las causas de variaciones patrimoniales y la materialización de ellas;

f) Incorporación de una flecha para expresar las transformaciones financieras de obtención y de asignación de recursos, para referirse a la obtención de estos desde el medio externo, ya sea por aporte de los dueños, de nuevos inversionistas, del crédito otorgado por entidades financieras y bancos comerciales y también para referirse, a la asignación de recursos que fluyen desde la empresa al entorno para devolver inversión a los inversionistas, para pagar intereses por créditos, para amortizar deuda, para devolver capital, para entregar la totalidad o parte de las utilidades que le corresponden a los dueños;

g) Aclaración que se utiliza el ciclo operacional de una empresa de naturaleza fabril, ya que este modelo se puede extrapolar y aplicar tanto para explicar el funcionamiento de empresas de naturaleza comercial o de empresas dedicadas a prestar solamente servicios.

Extrapolar y aplicar tanto para explicar el funcionamiento de empresas de naturaleza comercial o de empresas dedicadas a prestar solamente servicios, esto se puede observar en las Figuras 4b y 4c que se presentan a continuación (SILVA, 2008). 


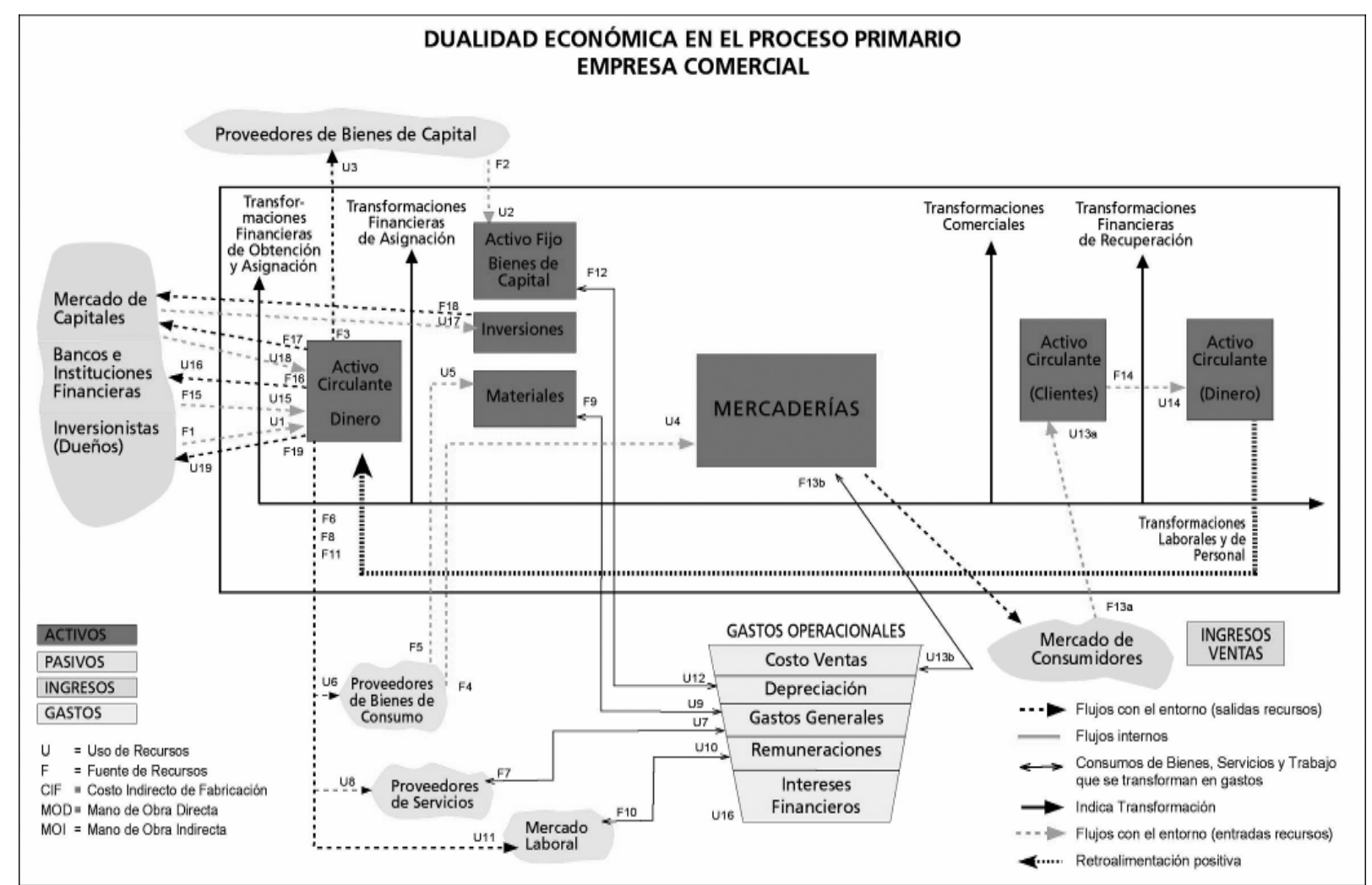

Figura 4b - Dualidad económica en el proceso primario de una empresa de comercial

Fuente: elaboración propia.

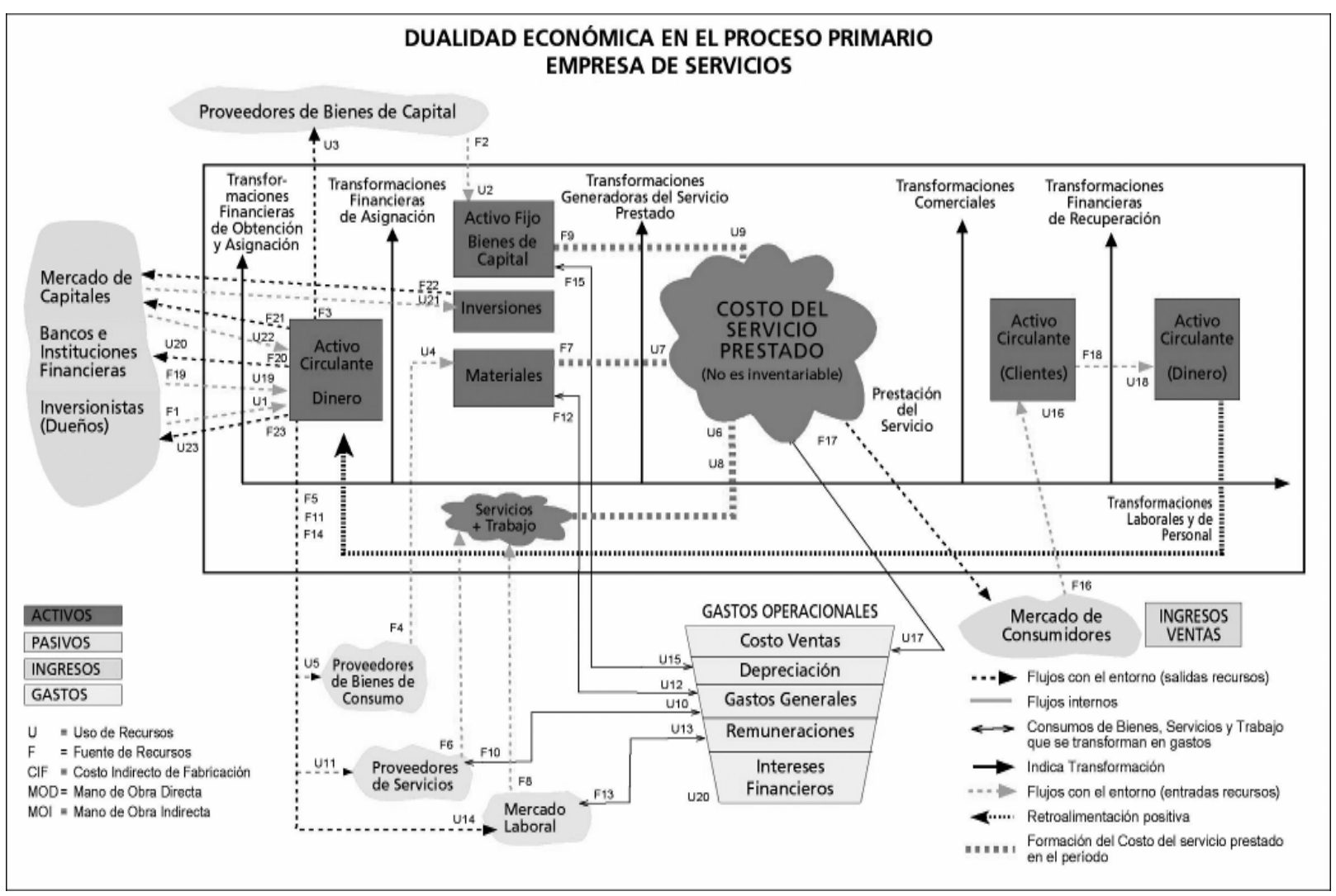

Figura 4c - Dualidad económica en el proceso primario de una empresa de servicios Fuente: elaboración propia. 
A través de la gráfica dualidad económica en el proceso primario se puede realizar varios procesos para gestionar la comprensión de fundamentos de la disciplina contable:

a) La identificación de los usos y de las fuentes en cada evento facilita la formulación del registro contable de cada hecho económico. El énfasis colocado en la dualidad económica, en usos y fuentes, facilita la comprensión de los conceptos de debe y de haber. Además contribuye a la comprensión que una misma partida o elemento contable, en algunos casos constituye uso y en otras fuente;

b) La comprensión de la relación de la empresa con el entorno y los procesos operacionales internos que se generan

c) La comprensión de los conceptos de entidad mercantil; empresa en marcha; período contable;

d) La comprensión de que en todo hecho económico se modifican partidas de activos y o de pasivos. Permite hacer evidente que cada hecho económico que se reconoce produce efecto sobre elementos contables de activos y o pasivos. Las transformaciones, derivadas de los hechos económicos que ocurren y en los cuales participa la empresa, afectan la estructura de sus recursos (activos) y de las obligaciones que recaen sobre los activos (pasivos) y también al derecho que los dueños tienen sobre los activos (patrimonio). Es en esta estructura en que se igualan los activos, con los pasivos y el patrimonio de la empresa, que se puede constatar un equilibrio con el medio en términos de los recursos obtenidos y de los recursos utilizados (dualidad económica);

e) La comprensión y distinción de los distintos elementos contables: activo, pasivo, patrimonio, y de los elementos informativos de la causa de variación del patrimonio ingreso, gasto, aportes, retiros. Se puede enfatizar que los cambios en el patrimonio, sean causados por las operaciones del negocio o por la acción de los dueños siempre se materializarán en variaciones de activos y/o pasivos (elementos contables reales)

f) La explicación del concepto de gasto, enfatizando que para reconocer este elemento contable se deben cumplir dos requisitos copulativos: i) debe ocurrir el consumo de bienes, de servicios, de trabajo o el uso del potencial de vida de un activo fijo, y, ii) el consumo o utilización de los recursos debe ser en el desarrollo de actividades administrativas o comerciales. Es decir, en actividades respecto de las cuales no se puede establecer si generarán beneficios en períodos futuros, o de hacerlo estos no pueden ser cuantificados o medidos confiablemente.

Bajo esta concepción, el consumo de servicios y/o trabajo al que se refiere, en el caso que corresponda al desarrollo de actividades de fabricación no podrán ser considerados gastos, ya que claramente se están realizando los consumos en actividades que generarán beneficios en períodos futuros, y que al menos pueden ser cuantificados por el costo. En todo caso, también se debe tener en cuenta y advertir al educando que existen modelos de costeo, que distinguen el tratamiento entre los costos de fabricación, aquellos que son fijos y los que son costos variables, pudiendo ser aplicado el sistema de costeo por absorción total o el sistema de costeo variable.

NIC 2 Inventarios - los costos de transformación de los inventarios comprenderán costos indirectos, variables o fijos, en los que se haya incurrido para transformar las materias primas en productos terminados. Además, facilita la explicación que 
el elemento contable Gasto es un concepto informativo de una variación negativa del patrimonio, que se materializa en disminuciones de activos y o aumentos de pasivos.

Es claramente distinguible que los servicios y trabajo consumidos en el desarrollo de actividades respecto de las cuales no se puede establecer si generarán beneficios en períodos futuros, o de hacerlo estos no pueden ser cuantificados o medidos confiablemente, se deben reflejar como gastos y no forman parte de la estructura de activos que se va formando con la acumulación de recursos resultantes de las transformaciones del ciclo operacional o proceso primario de la empresa.

g) La comprensión de que el conjunto de transformaciones va generando la estructura de activos y de pasivos que es claramente distinguible en la dualidad económica en el proceso primario, en donde se representan los activos circulantes (incluyendo el dinero) y los activos inmovilizados físicos, y también los pasivos;

h) La comprensión del concepto de acumulación, dada la necesidad de relacionar los recursos recuperados y auto generados (ingresos) con los recursos consumidos en el desarrollo de las transformaciones y en el mantenimiento de la estructura (costos y gastos) para explicar el concepto de acumulación;

i) La distinción del concepto de flujo y de estado, que luego facilita la comprensión del concepto de cuenta; de los informes del balance o estado de situación financiera (estado) y del estado de resultados (flujo). También facilita la distinción de flujos económicos y de flujos financieros;

j) La identificación y formulación de la estructura patrimonial de la empresa, la estructura de inversión y de financiamiento. El financiamiento con fondos propios y ajenos. Permite conocer el estado de la estructura de inversión y financiamiento de la empresa a una fecha dada, a través de la acumulación en las cuentas de los efectos en activos y/o pasivos y del saldo de cada una de ellas;

k) La distinción entre disponibilidades de dinero y resultados.

\section{APLICACIÓN DE LA METODOLOGÍA}

A través de esta metodología, utilizada en la formación básica de la disciplina contable, se busca entregar una visión global del sistema de contabilidad como sistema de información y de la relación de éste con el ciclo operacional básico de la empresa y con los agentes decisores que permiten la generación iterativa del mismo a través de las decisiones, que conllevan a acciones que generan procesos y transformaciones de recursos. También se persigue proporcionar los elementos del marco conceptual y normativo en que se sustenta.

La metodología propuesta permite que el educando relacione desde un comienzo las distintas disciplinas, tales como la administración, las finanzas y la contabilidad. Cuando el educando alcanza esta comprensión es posible que quede mejor preparado para poder diseñar sistemas de información contable-administrativo más adecuados para satisfacer las necesidades de información de los usuarios de ella.

Al comprender que la contabilidad como disciplina se ocupa del reconocimiento de los hechos económicos en los cuales participa la empresa y de los efectos que estos producen en su estructura de inversión y financiamiento, se facilita la aprehensión de los conceptos y procesos contables. Por esto es importante conocer las actividades que las empresas realizan día a día para lograr su auto sostenimiento y crecimiento, la correcta comprensión de estos hechos facilita el estudio de la contabilidad y la comprensión del conjunto de conceptos en los 
cuales se sustenta, referidos a: reconocimiento, valorización y revelación de los efectos que los hechos económicos producen.

Al comprender que el objetivo de la contabilidad es proporcionar información relevante para la toma de decisiones, información referida a las transformaciones que afectan a los recursos que posee y/o controla la empresa y los compromisos que recaen sobre ellos y que ellas se vinculan con las funciones operacionales de la empresa, es posible que profesionalmente estén más capacitados para preparar y proporcionar informes contables a los distintos usuarios de la información contable.

Al conocer y comprender desde un comienzo los elementos del marco conceptual de la contabilidad financiera que le otorgan el sustento a la normativa contable existente, es posible que el educando quede mejor preparado para enfrentar y solucionar situaciones nuevas respecto de las cuales no existe normativa específica para resolverlas.

En esta metodología, lo primero será entonces, explicar al educando a partir del modelo del proceso primario, como funciona la empresa tanto en sus aspectos administrativos como en los operacionales, su funcionamiento interno y su vinculación con el medio, es decir, con otras entidades y personas naturales. En esta etapa se deberá integrar los conceptos de la disciplina de la administración, resaltando los procesos de toma de decisiones y de control, y el rol que les compete a los agentes decisores en cada nivel de la estructura jerárquica de la empresa, y en la concreción del ciclo operacional o proceso primario, y en todo momento se debe enfatizar la importancia de la información en el desarrollo de estos procesos.

Se debe resaltar que los agentes decisores y los procesos que ellos conducen, se van concatenando y dando forma a la estructura organizacional de la empresa, que el sistema de información constituye la base de la integración de la estructura. Lo anterior, que se ha señalado tan simplemente, puede ser expresado utilizando los elementos aportados por Limone y Cademártori (1998), cuando definen y se refieren a los módulos de pilotaje y tecnológico, que en su opinión, constituyen los que llaman el eslabón básico de la estructura organizacional, esto quiere decir, que este eslabón básico está constituido por el acoplamiento entre el módulo de pilotaje y el módulo tecnológico, y que a través de acoplamientos sucesivos generan la estructura organizacional en la empresa.

Definen el módulo de pilotaje como la parte de la pareja estructural básica encargada de decidir la acción a realizar y, por lo tanto, la parte que activa, regula y coordina el desempeño de la unidad de ejecución; y al módulo tecnológico (o unidad de ejecución) como la parte de la pareja estructural encargada de realizar la acción y por lo tanto, el sujeto de activación, regulación y coordinación, a través de las variables esenciales que serán objeto de medición y control para asegurar la realización eficaz y eficiente de esa acción.

Se puede agregar que es el módulo que realiza la transformación de las entradas en salidas, que va produciendo los cambios de estado en el flujo de recursos que se produce en el desarrollo del ciclo básico operacional de la empresa (ver Figura 5 y Figura 6). 


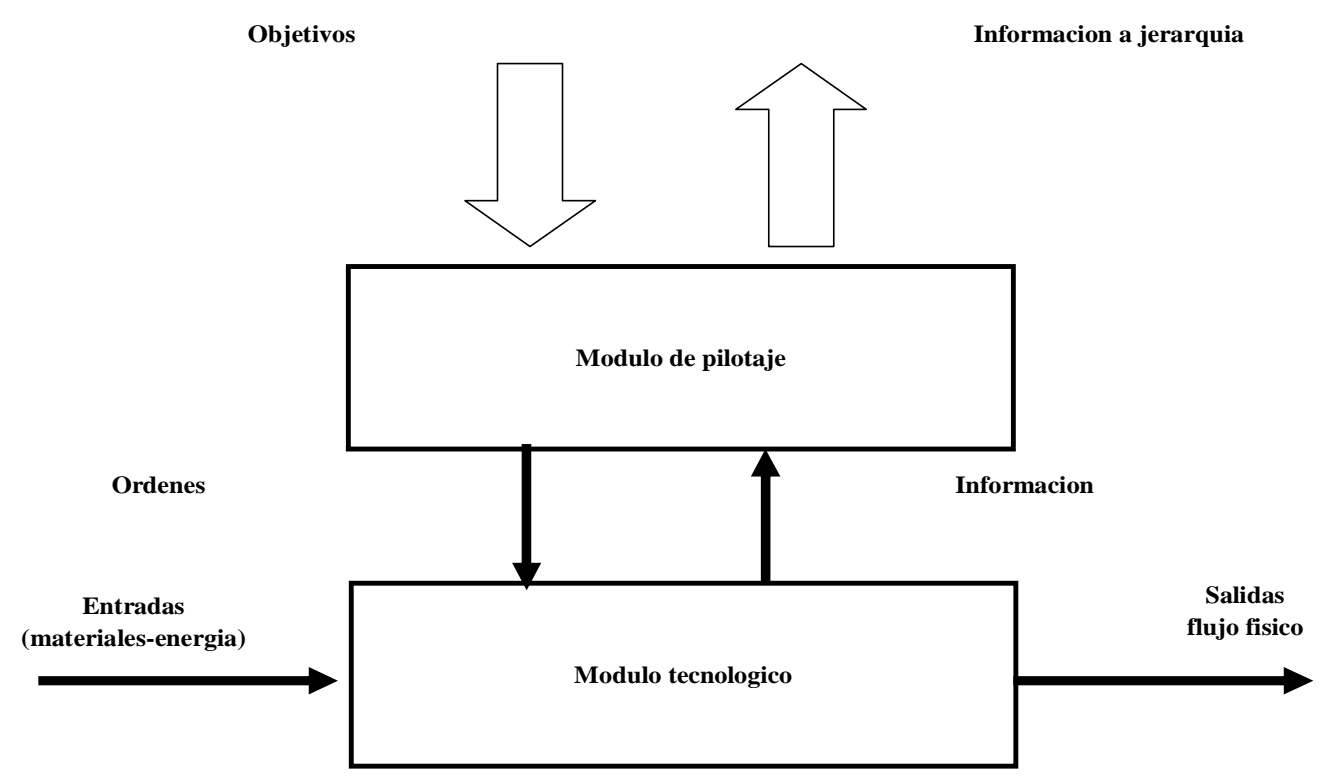

Figura 5 - Acoplamiento entre módulo de pilotaje y módulo tecnológico

Fuente: adaptación propia de Limone (2002).

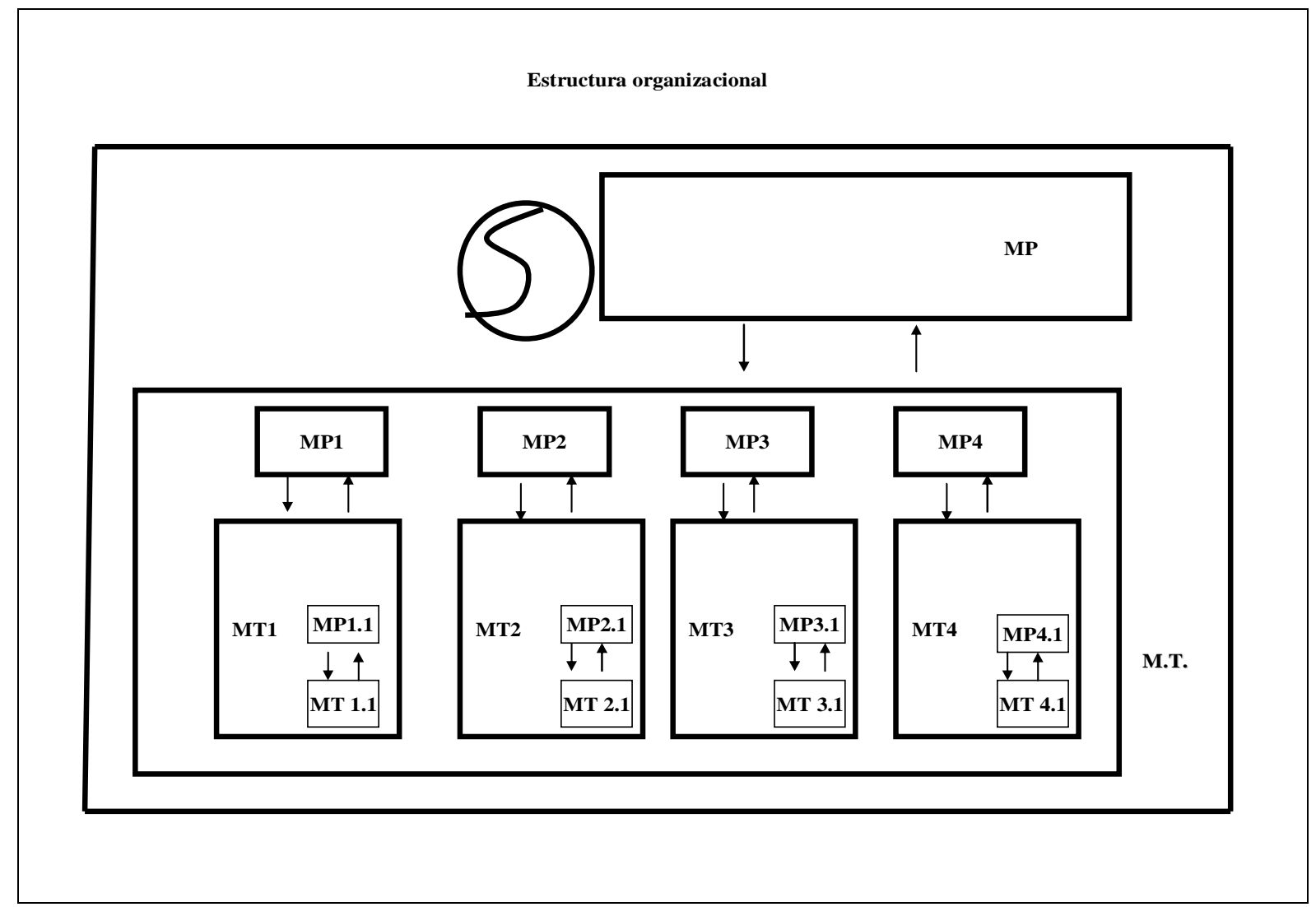

Figura 6 - Formación de la estructura organizacional

Fuente: Adaptación de Limone y Cademártori (2002). 
También definen las variables esenciales como aquellas variables de salida del sistema o módulo tecnológico, elegidas como criterios característicos de la realización de su misión o transformación principal, que permiten saber cómo está operando dicho módulo o sistema y que al ser comparados sus valores con un estándar u objetivo permiten controlar. Han definido las variables de acción, como los medios o palancas de comando a disposición de un piloto o regulador que le permiten corregir en permanencia la transformación entradassalidas. Implican necesariamente la toma de decisiones, y las variables de estado como las variables cuyos valores en un momento dado de observación nos permiten conocer el estado del sistema que estudiamos.

El acoplamiento se realiza a través de un sistema de información, que puede ser definido como una red comunicacional que comprende a toda la organización, a través de la cual fluyen decisiones y órdenes que permiten mantener integrada y funcionando a la misma y se regula a través de un sistema de control incorporado al sistema de información (Figura 7).

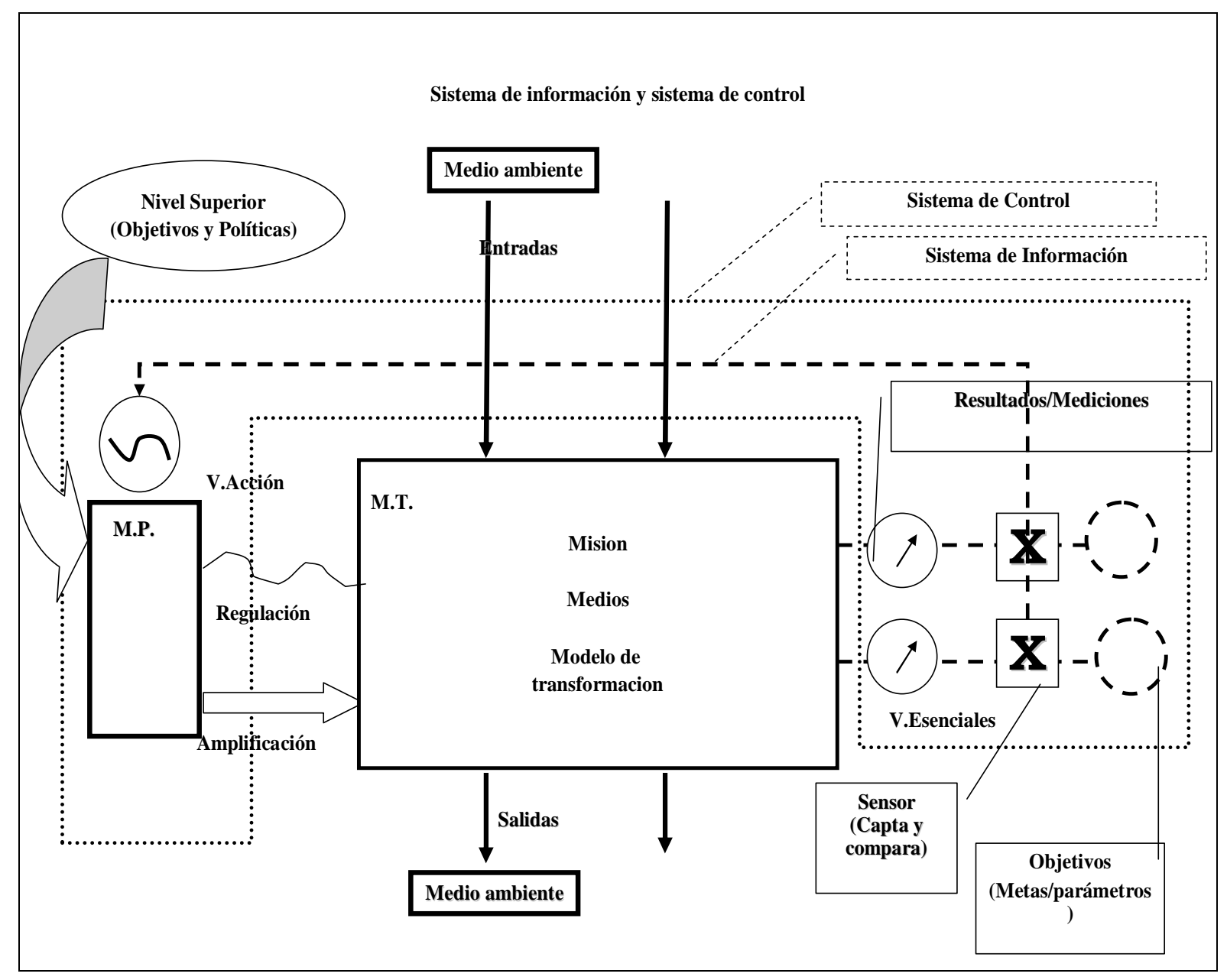

Figura 7 - Sistema de información y su relación con los módulos de pilotaje y tecnológico Fuente: adaptación de Limone (2002).

La empresa se constituye en el operar ininterrumpido y acoplado de tres procesos: el primario, el decisional y el de estructuración. El proceso decisional se define como una red conversacional cerrada, cuya actividad relativa se va especificando a cada instante, y en toda la amplitud del sistema, las coherencias operacionales necesarias en la producción de relaciones tecnológicas, laborales y económicas que constituyen al sistema en la red total de 
procesos. Limone (2002) señala que la red decisional implica la elaboración, procesamiento y flujo de información, en función de la cual, el proceso decisional, puede activar, regular y coordinar las transformaciones del proceso primario y sus propias transformaciones de información. Tener esta concepción clara contribuye a una mejor comprensión del rol e importancia de la contabilidad en la gestión de las organizaciones.

Se continúa definiendo la contabilidad desde un punto de vista sistémico y funcional, esto es, explicando que el sistema contable es un subsistema integrante del sistema de información de la empresa, capaz de identificar las transacciones que se originan en el ciclo operacional y reconocer los efectos económicos de éstas sobre la estructura de activos y de pasivos de la entidad, ocurridas durante un determinado período de tiempo, para proporcionar la información pertinente a los distintos usuarios. Ellos son los administradores de la empresa y los terceros que interactúan actual o potencialmente con la entidad, como son por ejemplo los agentes decisores en el mercado de capitales.

Con la información proporcionada se facilita la toma de decisiones y el control, basado en definición de Newton (1981). De la definición se desprende que existen distintos tipos de usuarios de la información: los internos y externos, en este punto se debe cuidar en señalar que la información contable es un tipo de información, ya que para realizar su gestión ellos requieren información que generan los otros subsistemas del sistema de información. El sistema de información se subdivide en subsistemas, dado que las funciones organizacionales y operacionales son variadas y tienen diferentes requerimientos de información. Es así como se puede distinguir, entre otros, los subsistemas de mercadotecnia, de producción, de personal, de finanzas.

El sistema de información de la empresa provee información, generada internamente y de la relación con el entorno, a la administración para apoyarla en las funciones de toma de decisiones, de gestión y de control, posibilitando el desarrollo de las operaciones y manejo de los recursos de la manera más eficiente. La información constituye un elemento imprescindible para la planificación, la gestión y el control. Cada nivel de procesamiento de información, cuando es necesario, utiliza los datos proporcionados por alguno de los otros niveles, también se incorporan nuevos datos sobre actividades o factores externos a la empresa y que la afecten o la puedan afectar. Las decisiones que tomen los administradores en la empresa, entendiendo como tales a aquellos que planifican, administran y controlan los procesos, necesariamente producirá acciones, sean correctivas, de asignación de recursos o de nuevos procesos.

En las organizaciones se pueden distinguir generalmente tres niveles de decisores: estratégico, táctico o de gestión, y operacional. Cada uno de estos niveles tiene distintos requerimientos de información, y a su vez retroalimenta al sistema de información con nuevos datos para generar más información, necesaria a los otros usuarios. A mayor nivel de responsabilidad en las decisiones se requiere información más global, en cambio al bajar hacia los niveles operativos la necesidad de desagregar o descomponer la información aumenta.

Se integran los conceptos proporcionados anteriormente, a través del diagrama presentado en la Figura 8. 


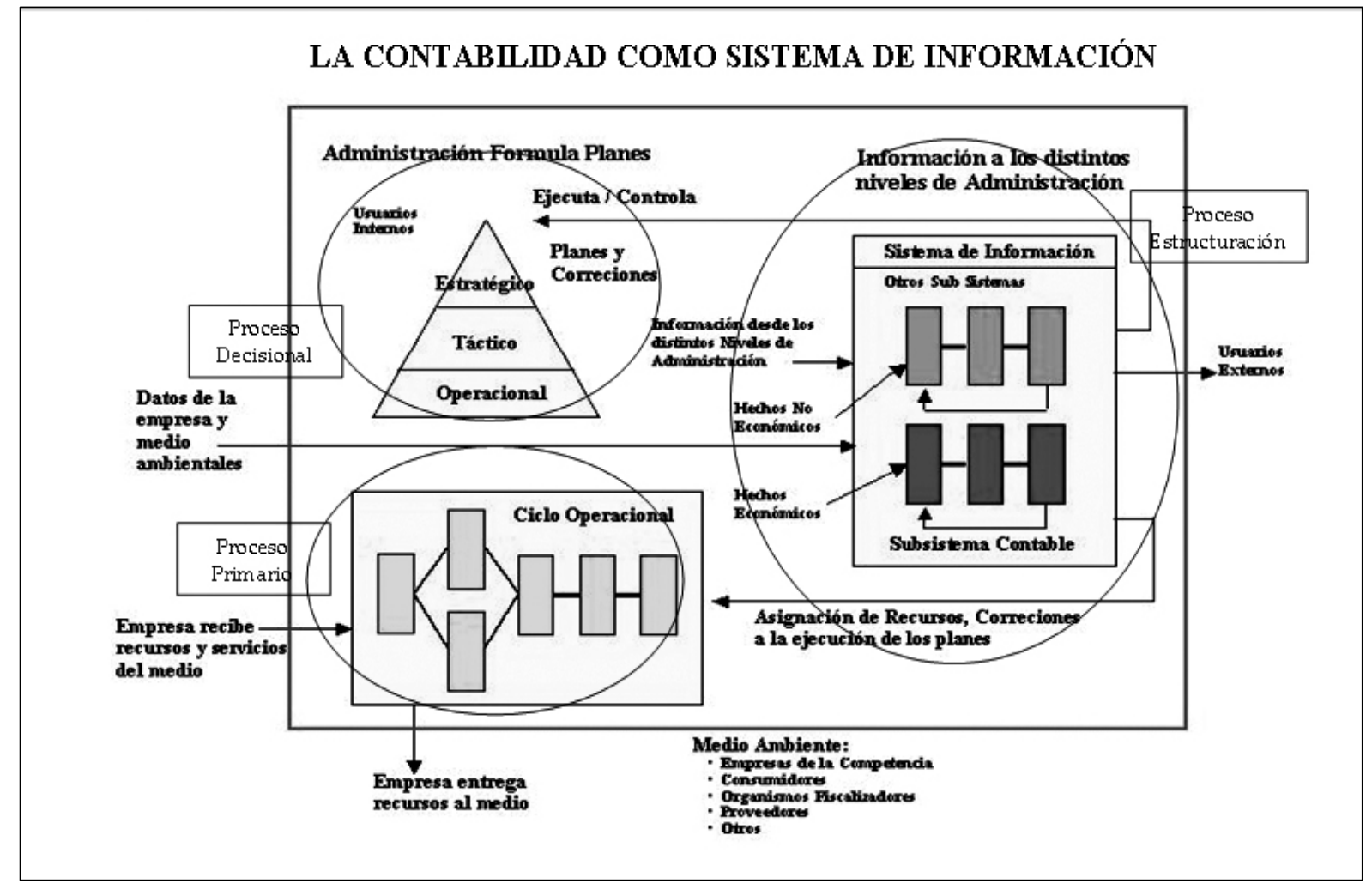

Figura 8 - Los usuarios y sus requerimientos de información

Fuente: elaboración de Silva (1996) complementado pelo Profesor Reinaldo Monardes, basado en definición de contabilidad de Newton (1981).

Es necesario referirse a la información, los requisitos y características de ella. El educando deberá entender la importancia que tienen tales aspectos, que dependerá a quien va dirigida la información y el propósito de su uso lo que definirá sus características y que todas ellas se complementan y no son excluyentes.

Dada la importancia que cobra en el mundo la normativa del International Accounting Standards Board (IASB), es imperativo que se incorpore la acepción que este organismo otorga a los conceptos propios de la disciplina contable.

Se continua bajo la óptica del proceso primario ordenando y explicando los aspectos contables que digan relación con las transformaciones que ocurren en este proceso. El proceso primario implica un intercambio de recursos con el medio, que supone necesariamente un equilibrio con este último en términos de los recursos obtenidos y de los recursos utilizados. Obviamente, otro intercambio importante y vital que se realiza, corresponde a la información.

Para cada transformación, sea financiera, comercial o de otra índole, se desarrollarán ordenadamente las siguientes tareas:

a) identificar el hecho económico. En esta fase, lo primero es precisar si conceptualmente existe o no existe un hecho económico. Se debe expresar cual es el hecho económico que comprende la transformación descrita, para ello se deben precisar y establecer las relaciones entre los distintos actores con relación al sujeto (la entidad mercantil) respecto del cual se mide su patrimonio y la evolución del mismo durante un período de tiempo;

b) identificar los usos y las fuentes. Basándose en el concepto de dualidad económica se debe establecer de dónde se han obtenido los recursos (las fuentes) y en qué se han utilizado (los usos), expresado de otra manera, se debe establecer la forma de 
financiamiento y la aplicación de los recursos en cada caso. Señalando el efecto sobre los activos y/o pasivos de la entidad.

Uso de fondos, es la utilización de ellos, que puede corresponder ya sea al aumento de un activo, a la disminución de un pasivo, también pueden consumirse en un gasto, en el pago de dividendos, devoluciones de capital, o simplemente pueden perderse. Los usos, se pueden identificar respondiendo entre otras interrogantes, a:

¿Se recibió algún recurso o dinero?

¿Se adquirió algún derecho o cuenta por cobrar?

¿En qué se utilizó el recurso o dinero entregado?

¿A quién se entregó el recurso o dinero? ¿A los dueños? ¿A los acreedores?

¿Se perdió algún recurso?

Fuente de fondos, es el origen de los fondos, de dónde provienen, puede ser del aumento de un pasivo, de la disminución de un activo, de las ventas, de aportes de capital o de ganancias originadas en hechos extraordinarios o que no son del giro. Las fuentes se pueden identifican respondiendo por ejemplo a:

¿Cómo se financió el recurso o servicio obtenido?

¿A quién se adeuda lo recibido o consumido?

¿Qué se entregó a cambio del recurso recibido, o del servicio consumido?

¿Cómo se financió?

c) determinar el efecto que el hecho económico provoca en el patrimonio de la empresa. Para cumplir tal propósito es imprescindible que se domine el concepto de patrimonio, pudiendo identificar si éste aumenta, si disminuye, o no es afectado como consecuencia del hecho económico. Se debe explicar como se distingue que el patrimonio ha cambiado;

d) determinar la materialización de los cambios patrimoniales. Distinguiendo el concepto de estructura patrimonial y el concepto de patrimonio, es pertinente enfatizar que todo hecho económico afecta a la estructura patrimonial (la estructura de activos y de pasivos de la empresa), sin embargo, no todo hecho afecta al patrimonio. Se debe indicar en cuáles partidas de activo y/ o de pasivo se materializa la variación del patrimonio;

e) determinar los conceptos informativos de las causas de las variaciones que sufre el patrimonio. Dado que los hechos económicos realmente solo afectan a las partidas del activo y/o del pasivo, y que cada vez que hay una variación patrimonial, es porque tales variaciones en la estructura de la dualidad económica no se compensan, se debe especificar cuál es la causa de ella mediante el uso de elementos contables informativos;

f) determinar el efecto que la transformación analizada genera en el flujo de caja de la empresa. Sobre la base de devengado se explica que los hechos económicos deben ser valorizados y registrados, independientemente de si afectan al flujo de dinero, entendiendo por tal sea el dinero efectivo o las disponibilidades en una entidad bancaria. Se debe determinar si el hecho económico produce un aumento, una disminución o no afecta al flujo de efectivo. Esto ayudará a diferenciar el flujo de disponibilidades del resultado.

El educando utilizando el concepto de dualidad económica podrá observar que cuando ocurre una variación patrimonial, necesariamente se modificará alguna partida de activo y/o pasivo y al mismo tiempo aparecerá un concepto informativo de la causa de variación. Lo 
anteriormente señalado no ocurre cuando el hecho económico no modifica al patrimonio, en ese caso solamente variarán partidas de activo y/o pasivo por igual valor.

Debe ponerse el énfasis en que, es en las partidas de activos y/o pasivos donde se materializan, se concretan, se evidencian los cambios patrimoniales; sin embargo, las causas de tales variaciones se revelan a través del uso de cuentas que son informativas, ellas no constituyen la variación patrimonial en sí mismas sino que, la razón u origen de la variación. Se habla del mismo fenómeno desde dos perspectivas distintas; la materialización y el origen o causa.

Se debe insistir que los conceptos que se utilizan para reflejar el cambio patrimonial son informativos, ya que éste se materializa solamente en el cambio del Activo Neto (Activo menos Pasivo). En este punto conviene resumir haciendo uso la Figura 9.

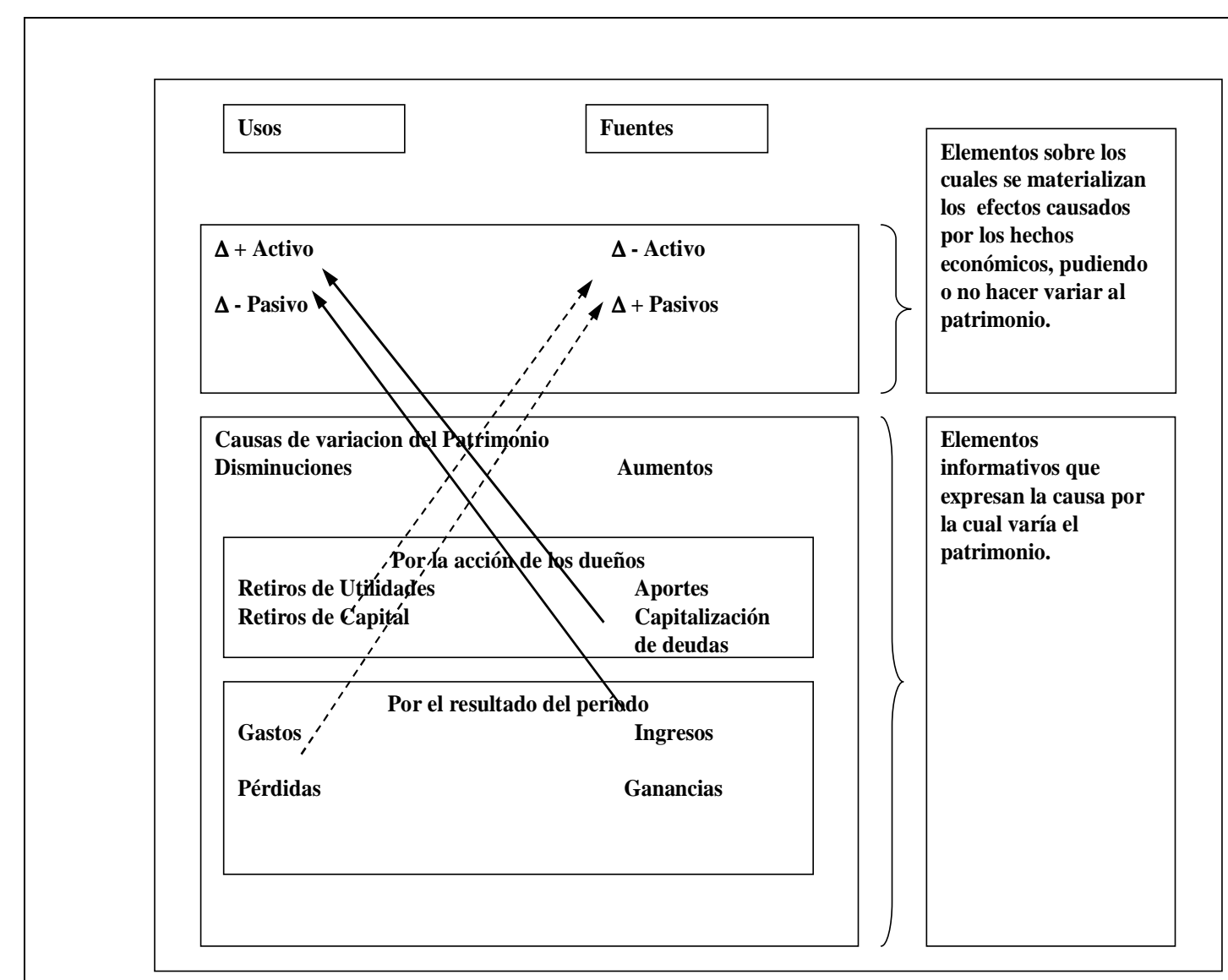

Figura 9 - Resumen de la materialización de los hechos económicos en activos y/o pasivos

Fuente: elaboración propia (2002).

Con esta gráfica, se demuestra que la variación del patrimonio se materializa en cambios de activo y/o pasivo, y que los conceptos de resultados solamente constituyen elementos contables informativos de las causas de la variación, sin embargo, no constituyen la variación en sí misma. Además, a partir del contenido de la misma se proporciona la base teórica que facilita la comprensión del concepto de cuenta y su tratamiento.

Así, en cada uno de estos procesos de transformaciones que constituyen el proceso primario, se va generando continuamente esta acumulación de recursos que determina la estructura patrimonial. Y la contabilidad estaría dando cuenta, en cada registro, de las 
transformaciones incrementales dentro del proceso continuo que significa el proceso primario, indicando como se mantiene y varía el equilibrio básico.

Lo más importante para comprender lo que realiza la contabilidad es aprehender el concepto de dualidad económica, es decir ser capaz de identificar y reconocer en cada hecho económico cuáles son los usos y sus respectivas fuentes. Ser capaz de establecer cuándo realmente en un hecho económico se está produciendo una variación patrimonial y utilizar correctamente el concepto informativo de la causa de ella.

Como el propósito del enfoque es proporcionar una formación integradora, mediante el uso de la Figura 10 ser relacionan el proceso primario, las funciones de la administración y el sistema de información contable.

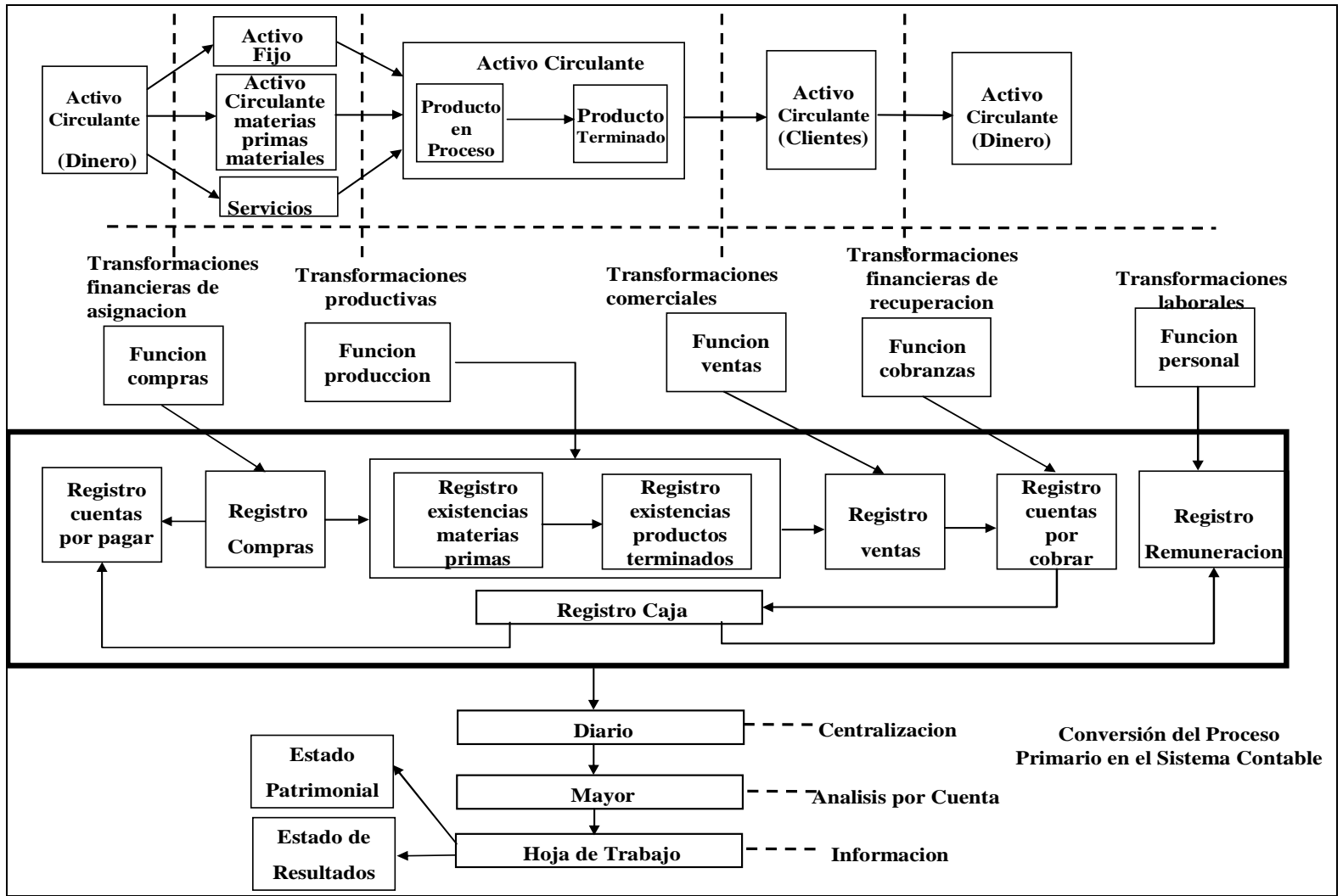

Figura 10 - Relación entre las funciones operacionales y administrativas con el sistema contable, en una empresa de naturaleza fabril

Fuente: elaboración conjunta con García (1996).

Aun cuando no se ha explicado detalladamente como se aplica esta metodología en la gestión del aprendizaje de los fundamentos de la disciplina contable, con lo presentado el lector dispone de los elementos básicos para comprenderla y constituye un punto de apoyo para que pueda adoptarla.

\section{CONCLUSIONES}

En esta metodología basada en el enfoque de la dualidad económica a partir del proceso primario:

a) los conceptos se van incorporando paulatinamente y basándose en el permanente raciocinio a partir del conocimiento entregado anteriormente. Se enfatiza el análisis que permite realizar el registro contable comprendiendo además del cómo hacer, el por qué del hacer. De manera que esta metodología permite interiorizar 
la base conceptual y práctica en materias contables promoviendo alcanzar el desarrollo de las conductas cognitivas a nivel crítico (es decir, fundamentar);

b) se facilita que el educando relacione desde un comienzo las distintas disciplinas, tales como la administración, las finanzas y la contabilidad;

c) se facilita la aprehensión de los conceptos y procesos involucrados en el sistema de información contable, comprendiendo que la contabilidad como disciplina se ocupa del reconocimiento de los hechos económicos en los cuales participa la empresa y de los efectos que éstos producen en su estructura de inversión y financiamiento;

d) se facilita desde un comienzo la comprensión de los elementos del marco conceptual de la contabilidad financiera que le otorgan el sustento a la normativa contable existente;

e) se facilita que el educando pueda distinguir fácilmente dos conceptos que serán fundamentales para comprender el concepto de cuenta y el de los informes contables. Esto debido a que cuando se revisa la dualidad económica presente en cada evento, lo que se hace es registrar el flujo y el efecto que va modificando $e l$ estado de las partidas contables afectadas.

La aplicación de la dualidad económica a partir del proceso primario permite una mejor comprensión y aplicación de los conceptos que fundamentan el registro contable y la generación de informes contables, el registro surge de un análisis y no de la simple expresión algebraica de la dualidad económica, que conlleva el riesgo de mecanizar al educando sin alcanzar una acabada comprensión de lo que realiza.

\section{REFERENCIAS}

ALVAREZ, Carlos; GARCÍA, María Teresa; NATTERO, Francisco. Una metodología docente para el área contable en la formación del contador público. En: Jornadas de Ciencias Económicas del ConoSur, 11., Buenos Aires, Argentina, 1983.

BOSCH, Julio; VARGAS, Luis. Contabilidad básica. 6. ed. Santiago, Chile: Soelco, 1995.

CANTÚ, Gerardo Guajardo. Contabilidad financiera. México: McGraw-Hill, 1995.

GARCÍA, María Teresa. Fundamentos y normativa de la contabilidad. Santiago, Chile: Editorial Jurídica Cono Sur Ltda., 2001.

HORNGREN, Charles; SUNDEM, Gary; ELLIOT, John. Introducción a la contabilidad financiera. 7. ed. Juárez, México: Prentice Hall, 2000.

LIMONE, Aquiles; CADEMÁRTORI, David. La empresa: una red de transformaciones. Santiago, Chile: Editorial Jurídica ConoSur Ltda., 1998.

LIMONE, Aquiles. L'autopoiese dans les organisations. Tesis (doctoral) - Université Paris IX Dauphine, Paris, Francia, 1977.

MEIGS, Robert; MEIGS, Mary; BETTNER, Mark; WHITTINGTON, Ray. Contabilidad: la base para decisiones gerenciales. 11. ed. Santafé de Bogotá, Colombia: McGraw-Hill, 1998.

MEIGS, Robert; WILLIAMS, Jan; HAKA, Susan; BETTNER, Mark. Contabilidad: la base para decisiones gerenciales. 11. ed. Santa Fe de Bogotá, Colombia: McGraw-Hill, 2000.

NEWTON, Enrique Fowler. Contabilidad básica. Buenos Aires, Argentina: Ediciones AVGVSTVS, 1981, pp.13-15. v. 2. 
NICOLINI, Mario; SOTO, Raúl. Contabilidad. Valparaíso, Chile: Ediciones Universitarias, 1978.

SILVA, Berta. Las empresas ya no requieren sólo empleados fríos, sino analistas para resolver problemas financieros. Diario La Patria, Oruro, Bolivia, octubre 2008.

SILVA, Berta. Una metodología de aprendizaje de la contabilidad coherente con los desafíos que impone la disciplina contable a nivel mundial. Revista Especial Facultad de Ciencias Económicas y Sociales, República Dominicana, Universidad Autónoma de Santo Domingo, diciembre 2008.

SILVA, Berta. Fundamentos del sistema contable: nuevos enfoques y actualización. 2. ed. Valparaíso, Chile: Pontificia Universidad Católica de Valparaíso, 2006.

SILVA, Berta. Desde el proceso primario: un enfoque para una comprensión más eficiente de la dualidad económica, el fenómeno contable. Tesis (Magíster en Gestión, mención Contabilidad y Finanzas) - Pontificia Universidad Católica de Valparaíso, Valparaíso, Chile, 2003.

SILVA, Berta. Metodología para el estudio de la contabilidad. Manual de contabilidad y auditoria, n. 118, p. 136-152, 2002.

SILVA, Berta. Causas y variación del patrimonio. Manual de Contabilidad y Auditoria, n. 119, p. 119-133, 2002.

SILVA, Berta. Transformaciones contables derivadas del proceso primario. Manual de Contabilidad y Auditoria, n. 120, p. 119-155, marzo, 2002.

SILVA, Berta. Metodología de enseñanza de la contabilidad. Revista Contabilidad, Auditoria e Impuestos, n. 58, p. 154-166, 1997.

SILVA, Berta. Metodología para la enseñanza de la contabilidad. En: Asamblea Permanente de Investigación Contable (CAPIC), 6., Serena, Chile, 1996.

TORRES, Gabriel. Contabilidad información y control en las empresas. 4. ed. Santiago, Chile: Editorial ConoSur Ltda., 2000.

WARREN, Carl S; REEVE, James M.; TESS, Philip E. Contabilidad financiera. México: International Thomson, 2000. 